\title{
SUEROS Y VACUNAS EN LA LUCHA CONTRA LA PANDEMIA DE GRIPE DE 1918-1919 EN ESPAÑA
}

\author{
María Isabel Porras Gallo
}

Universidad de Castilla-La Mancha

\section{RESUMEN}

En el marco de la renovada actualidad alcanzada por la pandemia de gripe de 1918-1919 en los últimos años y del protagonismo logrado por los estudios que analizan el proceso de innovación en Medicina, el presente trabajo analiza el papel representado por sueros y vacunas - los nuevos recursos de la ciencia médica del momento- en la lucha contra la gripe de 1918-1919. El estudio pone de relieve su dependencia de los factores científicos, sociales, económicos y profesionales que concurrieron, y muestra también las principales consecuencias derivadas de la puesta a punto y uso de los citados recursos terapéuticos y profilácticos.

PALABRAS CLAVE: Sueros. Vacunas. Gripe de 1918-1919. España. Siglo XX.

\section{SERUMS AND VACCINES TO FIGHT THE 1918-1919 INFLUENZA PAN- DEMIC IN SPAIN}

\begin{abstract}
Against the background of the renewed interest aroused in recent years by the influenza pandemic of 1918-1919, and the leading role now played by research analysing the process of innovation in medicine, this paper assesses the role played by serums and vaccines - the new resources of the medical science of the time - in the fight against the influenza outbreak of 1918-1919. The paper highlights the dependence on combined scientific, social, economic and professional factors, and also shows the main consequences arising from the fine-tuning and implementation of these therapeutic and prophylactic resources.
\end{abstract}

KEY WORDS: Serums. Vaccines. 1918-1919 influenza. Spain. 20th century.

\section{INTRODUCCIÓN}

Los años finales del siglo XX y el inicio del nuevo milenio confirieron renovada actualidad al estudio de las epidemias de gripe $\mathrm{y}$, muy concretamente, al análisis de la pandemia de 1918-1919. En efecto, la proximidad de su octo- 
gésimo aniversario y la presencia epidémica de la gripe aviar en los países asiáticos y, más tarde, su extensión puntual a algunos lugares de Europa y Canadá hicieron volver la mirada hacia la crisis epidémica más grave del siglo XX y la pandemia de gripe más importante de los últimos cien años por el número de muertes que ocasionó ${ }^{1}$. Se temió y se sigue temiendo que se pueda llegar a producir otra pandemia similar a la también denominada "gripe española ${ }^{2}$. En este sentido, se han efectuado diversas manifestaciones en los medios de comunicación social, tanto por parte de periodistas científicos como por algunos de los principales expertos en el tema. Gobiernos y organismos sanitarios internacionales han sometido a examen la situación y han diseñado algunos planes para tratar de evitar un desastre de magnitud semejante al que ocurrió hace ahora noventa años ${ }^{3}$. Se trata de tener a punto un dispositivo preventivo eficaz y, sobre todo, de contar con una vacuna válida contra la gripe aviar y contra la gripe humana que pudiera provocarse. De hecho, se ha estado probando una vacuna experimental contra el virus causante de la gripe aviar, que parece estar mostrándose efectiva ${ }^{4}$.

1 Esta situación propició la aparición de una literatura sobre la pandemia de 1918, elaborada mayoritariamente por periodistas científicos. De entre los títulos que pertenecen a este género, cabe mencionar los siguientes: IEZZONI, L. (1999), Influenza 1918. The worst epidemic in American history, New York, TV Books; KolATA, G. (1999), FLU. The story of the great influenza pandemic of 1918 and the search for the virus that caused it, New York, Touchstone Book; GETZ, D. (2000), Purple Death. The mysterious flu of 1918, New York, Henry Holt and Company, LLC; DAVIES, P. (1999), Catching cold. 1918's forgotten tragedy and the scientific hunt for the virus that caused it, $1^{\mathrm{a}}$ ed., London, Michael Joseph [En el año 2000 apareció una segunda edición con el título The devil's flu. The world's deadliest Influenza epidemic and the hunt for the virus that caused it, New York, Henry Holt and Company, LLC]. De rasgos similares, pero con un mayor apoyo documental es el libro de BARRY, J.M. (2004), The Great Influenza. The epic story of the deadliest plague in history, New York, Viking Penguin (existe una edición revisada de 2005).

2 Expresión de este estado de ánimo puede advertirse en: STEVENS, N. (2005), La gripe aviar, Málaga, Editorial Sirio (sobre todo en las pp. 69-71); PERENNE, J.-Ph.; BRICAIRE, F. (2005), Pandémie. La grande menace, Paris, Fayard; GARRET, L. (2005), The Next Pandemic?, Foreign Affairs, 84 (4), 3-23; Osterholm, M.T. (2005), Preparing for the Next Pandemic, Foreign Affairs, 84 (4), 2437. Inclusive, el equipo de investigación dirigido por el profesor Christopher Murray en la Universidad de Harvard ha llegado a estimar que una pandemia derivada de la actual gripe aviar podría ser responsable de la muerte de unos sesenta y dos millones de personas en el mundo (http://www.hsph.harvard.edu/press/releases/press12212006.html, consulta efectuada el 31-1-2007).

3 A modo de ejemplo, es interesante la consulta de PERENNE; BricAire (2005), pp. 203319, sobre la repuesta dada en Francia a esta eventual situación y el plan diseñado para evitarla.

4 «Dos nuevos estudios avalan la efectividad de una vacuna contra una futura pandemia de gripe aviar», El Médico Interactivo. Diario electrónico de la Sanidad, 1805, 7 de marzo de 2007 
Esta renovada actualidad alcanzada por la pandemia de gripe de 19181919 ha tenido su correlato en la historiografía sobre dicha crisis sanitaria, tratándose de compensar la tradicional falta de estudios históricos dedicados a dicha epidemia ${ }^{5}$. De hecho, a los trabajos que surgieron en los años ochenta e inicios de los noventa del pasado siglo en relación con el impulso que cobró el análisis de las epidemias tras la aparición del Sida ${ }^{6}$, se han añadido los realizados bajo el paraguas de la conmemoración del octogésimo aniversario de la pandemia. Algunos de ellos forman parte de la monografía de Howard y Killingray (2003), que recoge parte del contenido de la reunión que, con tal motivo, se celebró en Cape Town (Sudáfrica) en septiembre de 19987. La reflexión llevada a cabo en dicha reunión sobre la pandemia de 1918 y las nuevas perspectivas de estudio proporcionó interesantes interpretaciones so-

(Disponible en la siguiente dirección electrónica http://www.elmedicointeractivo.com/noticias_ext. php?idreg=14158, consulta efectuada el 7-3-2007).

5 Una sintética y ajustada visión sobre este tema, figura en: HowARD, Ph.; KILLINGRAY, D. (2003), Introduction. En Howard, Ph.; KIllingray, D. (eds.), The Spanish Influenza Pandemic of 1918-19. New perspectives, London, Routledge, pp. 1-25.

6 Entre los trabajos dedicados a dicha pandemia en nuestro país en esos años, cabe mencionar los siguientes: CARrillo, J.L.; CASTEllanos, J.; RAMOS, M.D. (1985), Enfermedad y crisis social: la gripe en Málaga (1918), Málaga, Universidad de Málaga, Secretariado de Publicaciones; Bernabeu Mestre, J. (coord.) (1991), La ciutat davant el contagi. Alacant i la grip de 1918-19, Valencia, Conselleria de Sanitat i Consum, Generalitat Valenciana; RodríGuEZ OCAÑA, E. (1991), La grip a Barcelona: un greu problema esporàdic de salud publica. Epidèmies de 1889-90 i 1918-19. En Cent anys de Salut Publica a Barcelona, Barcelona, Institut Municipal de la Salut, pp. 131-156; ECHEVERri DÁviLA, B. (1993), La gripe española. La pandemia de 1918-19, Madrid, Centro de Investigaciones Sociológicas-Siglo XXI; PorRas GALlo, Ma II. $^{\mathrm{a}}$ (1994a), Una ciudad en crisis: la epidemia de gripe de 1918-19 en Madrid, Tesis doctoral. Facultad de Medicina. Universidad Complutense de Madrid [publicada en CD-ROM en 2002 (Una ciudad en crisis: la epidemia de gripe de 1918-19 en Madrid, Madrid, Editorial Complutense), se encuentra disponible en http://www.ucm.es/eprints/2765/ (28-07-08)]; PORRAS GALLO, Ma.I. (1997a), Un reto para la sociedad madrileña: la epidemia de gripe de 1918-19, Madrid, Ed. Complutense-CAM; MARTínEZ, M. (1999), València al Limit. La ciutat davant l'epidemia de grip de 1918, Simat de la Valldigna, Edicions La Xara. Para un conocimiento más completo de las aportaciones realizadas en este tema dentro y fuera de España durante los años ochenta y noventa del siglo XX, se remite al lector a la bibliografía contenida en los trabajos citados y en Howard, Ph.; Killingray, D. (eds.) (2003), pp. 301-351; Johnson, N. (2006), Britain and the 1918-19 Influenza Pandemic. A Dark Epilogue, London/New York, Routledge, pp. 237-264.

7 El texto de Howard y Killingray (2003) recoge también una interesante y abundante bibliografía, que no es totalmente exhaustiva, pero que permite apreciar la marcha historiográfica sobre la denominada «gripe española» seguida en buena parte del mundo hasta finales del siglo $\mathrm{XX}$. 
bre las características del virus de la gripe de 1918, las reacciones de los médicos y enfermeras durante la pandemia (introduciendo la perspectiva de género en el análisis), la respuesta oficial de las autoridades políticas, el impacto demográfico (con numerosas contribuciones dedicadas al estudio de ámbitos aún no explorados), las consecuencias a largo plazo y en la memoria, y las lecciones epidemiológicas de la pandemia. En esta misma y fructífera senda se ha venido transitando en los últimos años, bajo el renovado impulso de las recientes epidemias de gripe aviar y la reconstitución del virus responsable de la pandemia de 1918 en el otoño de $2005^{8}$.

No obstante, con ser importantes las nuevas aportaciones ${ }^{9}$, es preciso señalar que aún restan algunos campos no suficientemente explorados. Uno de ellos es el referente al análisis del papel representado por los nuevos recursos profilácticos y terapéuticos que la ciencia médica usó para tratar de hacer frente a la pandemia de gripe de 1918-191910. Hasta ahora las aportaciones

8 Sobre la reconstrucción del virus de la gripe de 1918-1919 y sus principales características, pueden consultarse: TUMPEY, T.M. et al. (2005), Characterization of the Reconstructed 1918 Spanish Influenza Pandemic Virus, Science, 310, 77-80; STEVENS, N. (2005), La gripe aviar, Málaga, Editorial Sirio, pp. 70-71.

9 Además de los trabajos que conforman el texto de Howard y Killingray (2003), cabe mencionar los siguientes estudios histórico-médicos consagrados recientemente a la gripe de 1918-1919: LANGFORD, Ch. (2002), The Age Pattern of Mortality in the 1918-19 Influenza Pandemic: An Attempted Explanation Based on Data for England and Wales, Medical History, 46, 1-20; Johnson, N. \& Mueller, J. (2002), Updating the Accounts: Global Mortality of the 1918-1920 'Spanish' Influenza Pandemic, Bulletin of History of Medicine, 76, 105-115; AfKhami, A. (2003), Compromised Constitutions: The Iranian Experience with the 1918 Influenza Pandemic, Bulletin of History of Medicine, 77, 367-392; TOGNOTTI, E. (2003), Scientific Triumphalism and Learning from Facts: Bacteriology and the 'Spanish Flu' Challenge of 1918, Social History of Medicine, 16 (1), 97-110; FAHRNI, M. (2004), 'Elles sont partout...': Les femmes et la ville en temps d'épidémie. Montréal, 1918-1920, RHAF, 58 (1), 67-85; Guenel, J. (2004), La grippe 'espagnole' en France en 1918-1919, Histoire des Sciences médicales, 38 (2), 165-175; PORRAS GALlO, Ma .I. (2004), La epidemia de gripe de 191819 ¿Una pandemia evitable?, Eidon, 16, 45-48; LoEB, L. (2005), Beating the Flu: Orthodox and Commercial Responses to Influenza in Britain, 1889-1919, Social History of Medicine, 18 (2), 203-224; RICE, G. (2005), Black November: the 1918 influenza pandemic in New Zealand. $2^{\text {nd }}$ ed. ( $1^{\text {st }}$ ed., 1988), Christchurch, Canterbury University Press; JoHnsOn, (2006); SANTOS, R.A. DOS (2006), O Carnaval, a peste e a 'espanhola', História, Ciências, SaúdeMangunihos, 13 (1), 129-158; Macdougall, H. (2007), Toronto's Health Department in Action: Influenza in 1918 and SARS in 2003, Journal of the History of Medicine and Allied Sciences, 62 (1), 56-89.

10 De hecho, este tema no ha sido desarrollado en ninguno de los capítulos que componen el volumen de Howard y Killingray (2003), y es mencionado brevemente en el texto de BYER- 
sobre este tema se han limitado a unas pocas páginas o a pequeños comentarios incluidos en algunos artículos o libros sobre la epidemia, pero falta un estudio monográfico sobre ello ${ }^{11}$. Precisamente, tratando de contribuir a cubrir esta laguna historiográfica y haciéndonos eco del protagonismo que este tipo de estudios está cobrando en los últimos años en el marco del análisis del proceso de innovación en Medicina y en la práctica médica ${ }^{12}$, nos planteamos como objetivo principal del presente trabajo el examen del papel desempeñado por los sueros y las vacunas en la lucha contra la gripe de 1918-1919 durante su desarrollo en España. Además de indagar sobre los distintos tipos de sueros y vacunas propuestos y/o utilizados para hacer frente a la pandemia, se tratará de establecer cuáles fueron los principales factores que condicionaron su recomendación y/o su uso. Se prestará también atención al rol representado en todo el proceso por los médicos, los farmacéuticos y la prensa de informa-

LY, C.R. (2005), Fever of War. The Influenza Epidemic in the U.S. Army during the World War I, New York \& London, New York University Press.

11 Recientemente, hemos hecho un primer acercamiento monográfico a este tema (pero limitado al caso de las vacunas) en la ponencia que, bajo el título «Las vacunas como medio de establecer una profilaxis pública 'científica' contra la gripe de 1918-1919», presentamos en el IX Encuentro sobre Medicina y sociedad. Las vacunas: su historia y actualidad (Maó, 2122 de septiembre de 2006), y en la que, bajo el título «Una vacuna 'específica' para luchar contra la gripe de 1918-1919 en España», presentamos en el Coloquio Internacional 'Olhares sobre a Pneumónica' (Lisboa, 15-16 de noviembre de 2007). Se encuentran en prensa sendas versiones reelaboradas de dichos trabajos, que constituirán uno de los capítulos de los libros que recogerán el resultado de dichas reuniones. Igualmente, es preciso señalar que las vacunas usadas contra la gripe de 1918-1919 están comenzando a recibir la atención de otros investigadores. Uno de ellos es J. M. Eyler, que está preparando un artículo relativo a las controversias generadas sobre las vacunas contra la gripe que fueron probadas durante la pandemia de 1918-1919. Cfr. EYLER, J.M. (2006), De Kruif's Boast: Vaccine Trials and the Construction of a Virus, Bulletin of History of Medicine, 80, 409-438, p. 410.

12 Sobre la importancia otorgada a los sueros y las vacunas en los trabajos dedicados a analizar el proceso de innovación en Medicina, cabe mencionar las siguientes aportaciones: HALPERN, S. (2004), Lesser Harms. The Morality of Risk in Medical Research, Chicago/London, The University of Chicago Press, pp. 10-14, 41-65; BonAH, Ch. (2006), 'As safe as milk or sugar water': perceptions of the risks and benefits of the BCG vaccine in the 1920s and 1930s in France and Germany. En TrÖHLER, U. \& SCHLICH, Th. (eds.), The Risks of Medical Innovation. Risk perception and assessment in historical context, London/New York, Routledge, pp. 71-92; SCHLICH, Th. (2006), Risk and medical innovation: a historical perspective. En TRÖHLER, U. \& SCHLICH, Th. (eds.), The Risks of Medical Innovation. Risk perception and assessment in historical context, London/New York, Routledge, pp. 1-19; BLuME, S. (2006), The politics of Endpoints. En TimmermenN, C., Anderson, J. (eds.), Devices and Designs. Medical Technologies in Historical Perspective, Basingstoke, Palgrave Macmillan, pp. 249-272. 
ción general y obrera ${ }^{13}$. Igualmente, se apuntarán las consecuencias más importantes derivadas de la experiencia proporcionada por la gripe de 19181919 para la puesta a punto y/o empleo de los sueros y vacunas.

\section{UNAS PINCELADAS SOBRE EL DESARROLLO Y LAS CONSECUENCIAS DE LA PANDEMIA DE GRIPE DE 1918-1919}

A pesar de que, como hemos indicado anteriormente, la pandemia de 1918-1919 sea conocida como la "gripe española», su origen no estuvo en España. Este injusto calificativo, dado por la prensa europea de la época, derivó de nuestra condición de país neutral en la Primera Guerra Mundial y de la ausencia de censura militar. De forma que, aunque la epidemia había hecho su aparición en los países beligerantes de nuestro entorno, ésta se silenció hasta su inicio en Madrid a mediados de mayo. Como posibles orígenes de la pandemia la historiografía ha postulado Rusia, China y América, decantándose últimamente algunos investigadores por el origen americano y por su comienzo en un campamento del ejército estadounidense de Funston (Kansas) el 4 de marzo de 1918. Para otros autores fue China el punto de partida de la epidemia, y algunos han llegado a plantear la posibilidad de considerar ambos a la vez ${ }^{14}$. Desde los primeros focos, siguiendo las principales rutas de transporte habituales más las utilizadas en virtud de la situación de guerra que vivía el mundo, la gripe se extendió velozmente y alcanzó mayor extensión global que la Peste Negra. Responsables de este desarrollo tan virulento fueron no sólo los enormes desplazamientos humanos registrados durante el conflicto bélico y los propios efectos de éste, sino también el corto período de incubación de la gripe, su transmisión por vía aérea y la virulencia del virus responsable de la gripe de 1918-1919.

La pandemia cursó en tres brotes: el primero, en la primavera de 1918; el segundo, en el otoño de ese mismo año, y el tercero, en los primeros meses de

13 Además de monografías médicas y una selección de las principales revistas médicas españolas y foráneas, se ha utilizado como fuentes una selección de prensa general $(A B C, E l$ Heraldo de Madrid, El Liberal y El Sol) y obrera (El Socialista) de los años de la pandemia con la intención de cubrir un amplio espectro desde posturas más próximas al régimen hasta posiciones más críticas, independientes o de izquierdas, contando también con prensa de carácter más informativo y en el caso de $\mathrm{El} \mathrm{Sol} \mathrm{con} \mathrm{un} \mathrm{particular} \mathrm{interés} \mathrm{por} \mathrm{los} \mathrm{temas} \mathrm{médicos.}$

14 En relación con el origen de la pandemia de gripe de 1918-19, puede consultarse: PoRRAS GALLO, Mª.I. (1994a) [2002], pp. 72-76. (De ahora, en adelante se citará por la versión en CD-ROM de 2002). 
1919. Aunque hubo variaciones en su desarrollo de unos lugares a otros, la «gripe española» registró elevadas tasas de morbilidad y mortalidad, habiéndose estimado inicialmente que provocó 20 millones de muertos ${ }^{15}$. Sin embargo, los estudios realizados en los últimos años consideran que esa cifra es muy inferior a la realidad, hablándose de 30,50 e incluso de 100 millones de víctimas por la gripe ${ }^{16}$. A esa cifra habría contribuido nuestro país con unas 270.000 muertes, siendo el segundo brote el que produjo mayor número de víctimas en la mayor parte de España ${ }^{17}$, salvo en la ciudad de Madrid ${ }^{18}$. En esta ocasión, a diferencia de lo que suele ocurrir en las epidemias de gripe, las víctimas preferidas de la pandemia de 1918-1919 fueron los jóvenes, registrándose la mayor morbimortalidad entre las personas de 20 a 40 años. Precisamente, la gran repercusión que tuvo en la población activa entrañó un negativo efecto en la economía y una enorme conmoción social no sólo en nuestro país, sino también en el resto del mundo.

\section{LA LUCHA CONTRA LA «GRIPE ESPAÑOLA» EN EL MARCO DEL PARADIGMA BACTERIOLÓGICO}

A la vista de la gravedad que alcanzó la pandemia y de sus principales características es lícito pensar que los recursos utilizados para enfrentarse a la «gripe española» tuvieron escaso o nulo efecto, e incluso cabe preguntarse hasta qué punto se contó con medios efectivos para luchar contra ella. Sin embargo, en el momento en el que la epidemia estalló la Medicina creía estar viviendo una etapa triunfalista frente a la patología infecciosa. En efecto, desde que el desarrollo de la doctrina bacteriológica se acompañó de un mejor conocimiento etiológico de las enfermedades infecciosas y de la posibilidad de disponer de recursos efectivos frente a ellas, la Medicina se creyó capaz de controlar los procesos infecciosos y los médicos empezaron a referirse a ellos

15 Jordan, E.O. (1927), Epidemic Influenza: A Survey, Chicago, American Medical Association, pp. 214-218.

16 Patterson, K.D. \& Pyle, G.F. (1991), The Geography and mortality of the 1918 influenza pandemic, Bulletin of History of Medicine, 65, 4-21, pp. 5 y 21; JOHNSON \& MUELLER (2002), p. 115.

17 ECHEVARRi DÁvila (1993), pp. 120-122.

18 En Madrid fue el primer brote el que alcanzó mayor intensidad. PORRAS GALLO, M ${ }^{\mathrm{a}}$.I. (2002), pp. 212-239; PORRAS GALlo, Ma .I. (1997a), pp. 52-65; PORRAS GALlO, Ma..I. (1996), Las repercusiones de la pandemia de gripe de 1918-19 en la mortalidad de la ciudad de Madrid, Boletín de la Asociación de Demografía Histórica Española, 14 (1), 75-116. 
como «enfermedades evitables» ${ }^{19}$. Éste era el estado de opinión dominante dentro de nuestras fronteras cuando comenzó la gripe de 1918-1919. Conforme a él, parecía viable enfrentarse a la situación epidémica, pero era preciso hacerlo de una determinada forma al tratarse de una enfermedad de carácter infeccioso. De ahí que, cuando en mayo de 1918 se inició la epidemia en Madrid, los médicos debían diagnosticar cuál era la enfermedad responsable de la misma, no sólo mediante la observación del cuadro clínico, sino también recurriendo a la investigación bacteriológica. Así, el diagnóstico clínico de gripe, que los médicos realizaron desde los primeros momentos de la epidemia, tenía que ser corroborado por el laboratorio ${ }^{20}$. Era necesario, por tanto, efectuar el aislamiento del bacilo de Pfeiffer, considerado entonces oficialmente como el germen específico de la gripe ${ }^{21}$. Una vez conseguido esto, el siguiente paso era proceder a la preparación de un suero y una vacuna específicos contra dicho bacilo, que se convirtieran respectivamente en las medidas terapéutica y profiláctica contra la «gripe española».

\section{LAS DIFICULTADES DEL LABORATORIO: UN FRENO PARA EL ESTABLECIMIEN- TO DE UN TRATAMIENTO ESPECÍFICO CONTRA LA GRIPE}

Ahora bien, aunque médicos, farmacéuticos y veterinarios se entregaron a dicha tarea desde el comienzo, los resultados que brindó el laboratorio no permitieron corroborar el papel del bacilo de Pfeiffer como agente etiológico de la gripe. Las investigaciones bacteriológicas tampoco aportaron ningún otro agente que cumpliera los postulados de Koch, y, a lo largo de los tres brotes epidémicos, se consideraron numerosas hipótesis etiológicas, que en la

19 De esta cuestión, nos hemos ocupado en PorRas GaLLO, Mª.I. (1994b), La lucha contra las enfermedades 'evitables' en España y la pandemia de gripe de 1918-19, Dynamis, 14, 159-183.

20 En este sentido se expresó el médico José Codina Castelví (1867-1934). Cfr. «Sesión del 25 de mayo de 1918», Anales de la Real Academia de Medicina (ARAM, en adelante), 38, (1918), 310-319, p. 312. Mayor información sobre este tema, puede encontrarse en: PORRAS GALLO, M.I. (2002), pp. 294-439.

21 La aceptación de la etiología bacteriana de la gripe en la pandemia de 1889-90 entrañó la búsqueda de su agente específico, pero no fue hasta 1892 cuando Richard Pfeiffer (18581945) aisló el bacilo que lleva su nombre y lo consideró el bacilo de la influenza. Con posterioridad se hicieron algunas objeciones e incluso se cuestionó la especificidad de dicha bacilo en la epidemia gripal de 1904-05. PigA, A., LAMAS, L., (1919), Infecciones de tipo gripal, Madrid, Talleres tipográficos de «Los Progresos de la clínica» y «Plus Ultra», 2 vols., t. I, pp. 125-128, 137-145; THÉODORIDĖs, J. (1974), La microbiología médica. En LAÍN ENTRALGO, P. (dir.), Historia Universal de la Medicina, Barcelona, Salvat Editorial, 1ª ed., t. 6, 175-192, p. 188. 
mayoría de los casos no eran novedosas, sino que habían sido formuladas a lo largo de la historia bacteriológica de la gripe ${ }^{22}$. Mientras algunos se mantuvieron fieles al dogma oficial y siguieron defendiendo el papel del bacilo de Pfeiffer, otros trataron de adaptarse a los resultados del laboratorio y propusieron una asociación bacteriana (estreptococos, neumococos, meningoco$\cos . .$.$) , que se reveló más relacionada con las complicaciones, o bien se de-$ cantaron por una única bacteria distinta del bacilo de Pfeiffer. A su vez, los partidarios de una etiología microbiana de la gripe, que actuaron con mayor rigor frente a los resultados del laboratorio, optaron por considerar que el agente etiológico de la gripe era un germen desconocido. Algunos de ellos dieron incluso un paso más a medida que se desarrollaba la epidemia y se convirtieron en defensores de la hipótesis más atrevida, que proponía que el agente de la gripe era un virus filtrable.

Ante la imposibilidad de aclarar la etiología de la enfermedad epidémica, algunos médicos mostraron su convencimiento de que, como señaló Hergueta, no se podía disponer de «un medicamento verdaderamente específico contra la gripe $»^{23}$. Esta opinión se fue generalizando conforme el segundo brote de la epidemia alcanzaba su punto álgido en nuestro país. De hecho, la falta de «un procedimiento terapéutico específico, de eficacia decisiva para el tratamiento de la gripe y sus complicaciones» ${ }^{24}$ fue también reconocida por la Real Academia de Medicina. Algunos médicos, como B. González Álvarez (18511927), fueron aún más claros en sus manifestaciones, afirmando que «tratamiento patogenético-etiológico no lo hay ni lo puede haber, porque se desco-

22 Una descripción más detallada del debate etiológico registrado durante la pandemia de 1918-1919, figura en: PORRAS GALlo, Ma..I. (2002), pp. 311-327; PORRAS GALlo, M M $^{\mathrm{a}}$.I. (1993), La Real Academia Nacional de Medicina y la problemática sobre la etiología de la gripe en la epidemia de 1918-1919. En GonZÁlez DE PABLO, A. (coord.), Enfermedad, Clínica y Patología. Estudios sobre el origen y desarrollo de la Medicina Contemporánea, Madrid, Editorial Complutense, pp. 103-128; PORRAS GALLO, M ${ }^{a}$.I. (1995), La epidemia de gripe de 1918-19: una oportunidad para evaluar la recepción de ideas científicas en el pensamiento médico español. En ArQuiola Llopis, E., MARTínez PÉrez, J. (coord.), Ciencia en expansión. Estudios sobre la difusión de las ideas científicas y médicas en España (Siglos XVIII-XX), Madrid, Editorial Complutense, pp. 247-265. Una buena síntesis del desarrollo de este mismo debate en Italia es el trabajo de ToGNOTTI, E. (2003), pp. 97-110 (st. pp. 102-109).

23 «Sesión del 26 de octubre de 1918», ARAM, 38 (1918), 403-424, p. 414. Agustín Cañizo, catedrático de Medicina de Salamanca, compartió la opinión de Hergueta y consideró totalmente infundado el empleo de sueros (antidiftérico, estreptocócico o cualquier otro). CAÑIZO, A. DEL (1918), Opinión de los clínicos, España Médica, 8 (280), 1-11-1918, 8-11, p. 10.

24 «Sesión del 23 de noviembre de 1918», ARAM, 38, (1918), 511-528, p. 527. 
noce el germen único específico» ${ }^{25}$. Ante esta situación, el citado autor reconocía que «las indicaciones que pueden hacerse no son más que de índole general, de activar las defensas orgánicas y mantener las energías vitales» ${ }^{26}$. Esta opinión fue compartida por la mayoría de los médicos. De ahí que, ante la necesidad de ofrecer una respuesta terapéutica a la sociedad enferma, propusieran una gama amplia y diversa de recursos con los que se pretendía combatir los síntomas, activar las defensas orgánicas y mantener las energías vitales de los enfermos de gripe. Fueron utilizados antipiréticos, sudoríficos, tónicos, excitantes, baños, purgantes, desinfectantes, aireación sana, dieta sana e incluso la sangría, adoptando cada médico su propia combinación terapéutica $^{27}$. Exponente de esta diversidad terapéutica fue la respuesta dada por la Real Academia de Medicina al ministro de la Gobernación el 29 de octubre de 1918 sobre los tratamientos considerados por dicha institución como eficaces contra la gripe de 1918-1919. En dicha respuesta figuraron como medicamentos los siguientes productos:

«Sales de quinina, opio y sus derivados, yodo y yoduros, digital y sus derivados, acetato y carbonato amónicos, antipirina, aspirina, entorina, piramidón, esparteína y sus sales, cafeína y sus sales, estricnina y sus sales, adrenalina, colesterina, benzoato sódico, alcanfor, salicilato sódico, novocaína» ${ }^{28}$.

Junto a los productos mencionados, la respuesta de la Academia incluyó desinfectantes (Cresol, creolina y demás derivados de la hulla, hipocloritos, azufre y formol) y sueros ${ }^{29}$.

25 «Sesión del 23 de noviembre de 1918», ARAM, 38, (1918), 511-528, p. 516.

26 Ibíd.

27 Así, para Baltasar Hernández Briz (1857-19??), como indicó en la sesión de la Real Academia Nacional de Medicina del 1 de junio de 1918, el tratamiento de la gripe debía consistir en la combinación de «los baños generales, la salipirina y la quinina como tónico; y todo esto precedido de un purgante, bien el aceite de ricino o bien los calomelanos». «Sesión del 1 de junio de 1918», ARAM, 38, (1918), 353-359, pp. 354-355. Información más completa sobre esta multiplicidad de tratamientos contra la gripe propuestos por los médicos durante la pandemia de 1918-1919 en nuestro país, figura en PORRAS GALlO, Ma'.I. (2002), pp. 346-352.

28 Archivo de la Real Academia Nacional de Medicina. Carpeta 289 (Papeles diversos. Años 1918-1919). "Carta fechada el 29 de octubre de 1918 y dirigida a la Real Academia Nacional de Medicina por la Inspección General de Sanidad, Ministerio de la Gobernación», en la que se pregunta sobre «los medicamentos más indispensable en el tratamiento de la gripe, con el fin de poner remedio a la escasez de ellos en el mercado y evitar el acaparamiento y el exceso de precio de los mismos», y «Respuesta que dio la Academia a la cuestión».

29 Ibíd. 
5. LA BÚSQUEDA DE UN TRATAMIENTO «CIENTÍFICO» BAJO LA PRESIÓN SOCIAL: DEL SUERO ANTIDIFTÉRICO A LOS SUEROS ANTINEUMOCÓCICO Y ANTIESTREPTOCÓCICO

Como vemos, el listado de la Academia incorporó igualmente los nuevos recursos terapéuticos. Concretamente, se mencionaban el «suero antidiftérico, equino y demás sueros» ${ }^{30}$. Ahora bien, es preciso tener en cuenta que no todos los médicos consideraron desde la misma perspectiva el valor de los sueros para luchar contra la gripe, siendo para algunos meros recursos para activar las defensas generales del organismo. De ahí que no nos deba extrañar que la opinión frente a ellos estuviera dividida y se suscitaran amplios debates no sólo en la Academia de Medicina, sino también en otros muchos foros como el Congreso, el Senado, el Real Consejo de Sanidad, las principales revistas científico-médicas o la prensa de información general, especialmente durante el momento de máxima intensidad del segundo brote. Así, Tomás Maestre (1857-1936) se mostró firme partidario y defensor del valor del suero antidiftérico para luchar contra la epidemia reinante, manifestando en la sesión del Senado del 25 de octubre de 1918 que «el suero antidiftérico [era] el remedio más eficaz contra la gripe en todas sus formas» ${ }^{31}$, y solicitando su producción en grandes cantidades, empleando para ello caballos del Ejército que debía adquirir el Instituto de Higiene Alfonso XIII. Mientras que en ese mismo foro Espina y Capo (1850-1930) afirmó que el suero antidiftérico era tan sólo uno de tantos tratamientos contra la gripe ${ }^{32}$.

El revuelo social provocado en torno a este tema impulsó al ministro de la Gobernación a recabar la opinión de la Real Academia de Medicina y trasladar el debate al seno de dicha institución. En la sesión celebrada en la Academia el 26 de octubre se registró una intensa discusión acerca de la eficacia del suero antidiftérico contra la gripe y de su producción a gran escala. Como cabía esperar, Maestre mantuvo su postura favorable al valor del suero antidiftérico, pero la mayoría de los académicos compartió la posición de Espina. De hecho, entre otros, Hergueta, Francisco Murillo (1865-1944), Francisco

30 Ibíd.

31 «Sesión del 25 de octubre de 1918», Libro de Actas de las Sesiones de las Cortes. Senado, 83, legislatura 1918-1919, 1471-1475, pp. 1471-1472. Maestre había expuesto esta misma opinión en la prensa general en el momento álgido del primer brote. MAESTRE, T. (1918a), La epidemia de gripe. Los Doctores siguen opinando. El [Dr.] Maestre, El Heraldo de Madrid, 6-6-1918, portada.

32 «Sesión del 25 de octubre de 1918», Libro de Actas de las Sesiones de las Cortes. Senado, 83, legislatura 1918-1919, p. 1475. 
Huertas (1847-1933), Amalio Gimeno (1852-1936), Martín Salazar (18541936), Antonio Simonena (1861-1941), González Álvarez y José Codina (1867-1934) insistieron en que el suero antidiftérico no tenía ninguna acción específica sobre la gripe ${ }^{33}$. Como indicaron Gimeno y Huertas, dicho suero estimulaba las defensas orgánicas, razón por la que para este último «era un buen agente terapéutico, pero no específico de la infección gripal» ${ }^{34}$. En una línea similar, para Martín Salazar, desde el punto de vista de la Teoría de la Inmunidad, el suero antidiftérico era únicamente específico contra la difteria y poseía una relativa eficacia frente a otras infecciones ${ }^{35}$.

De una forma más contundente se mostró Simonena al indicar que, «ni desde el punto de vista teórico, ni desde el punto de vista experimental, ni clínico», se podía hacer otra afirmación que la de que el suero antidiftérico no era «un medicamento específico en los casos de gripe» ${ }^{36}$. Este médico relacionaba las posturas como la de Maestre con el hecho de que «la gente, ante los estragos que produce la epidemia, reclama con urgencia la indicación de remedios con que poder oponerse al avance del mal», y en esa situación el médico deseoso de calmar semejante inquietud y ansiedad adopta posiciones como la de Maestre ${ }^{37}$. Para comprender la importancia que esa necesidad de responder a las demandas de la sociedad de la que hablaba Simonena poseía en esos momentos, conviene recordar que se trataba de ofrecer soluciones a una población expuesta a un ambiente presidido por la imagen de la muerte, que cuestionaba la labor de los políticos y de las autoridades sanitarias, que se hallaba confusa ante la anarquía científica reinante y que empezaba a dudar de la capacidad de los médicos y de la Medicina para hacer frente a la epidemia $^{38}$. Esto último tenía especial relevancia, dada la magnitud de la epidemia y dado el interés de los médicos en esos momentos por dar muestras de su alto nivel científico y preparación para desempeñar en la sociedad española el importante papel, que estaban reclamando desde las décadas finales del siglo XIX, y que adquirió renovada actualidad durante la pandemia ${ }^{39}$.

33 «Sesión del 26 de octubre de 1918», ARAM, 38, (1918), pp. 403-424.

34 Ibíd., pp. 415-416.

35 Ibíd., pp. 417-419.

36 Ibíd., pp. 419-420.

37 Ibíd., p. 420.

38 Mayor información acerca del estado de ánimo de la población española y sus reacciones, figura en: PORRAS GALlO, Ma.I. (2002), pp. 595-638; PORRAS GALLO, Ma.I. (1997a), pp. 117-132; MARTíneZ, M. (1999), pp. 81-142; Bernabeu Mestre, J. (coord.) (1991), pp. 100-124.

39 Sobre la situación profesional de los médicos, véanse: PORRAS GALLO, Ma.I. (2002), pp. 373-394; PORRAS GALLO, Mª.I. (1997a), pp. 107-109. 
Considerando muy probablemente todas estas circunstancias que concurrían, Grinda llamó la atención de los académicos sobre el hecho de que se podía plantear un «conflicto de orden social de una gravedad extraordinaria» si la Academia admitía que el suero antidiftérico era eficaz contra la gripe y se reconocía que no había suficiente para todos ${ }^{40}$. De hecho, aunque Grinda no lo mencionó, su falta fue denunciada tanto en las sesiones del Congreso del 24 y 25 de octubre, como en la prensa científico-profesional y en la prensa general ${ }^{41}$. Finalmente, tras el intenso debate registrado, la Academia concluyó que «el suero antidiftérico en la gripe es un remedio útil, pero no específico, puede ser sustituido con el suero normal equino», $\mathrm{y}$ «éste puede prepararse fácilmente en los laboratorios, precisando para ello caballos sanos» ${ }^{42}$.

Esta conclusión, sin embargo, no parece que fue bien recibida por Gustavo Pittaluga (1876-1956), uno de los miembros de la Comisión nombrada por el Gobierno para estudiar el desarrollo de la epidemia y las medidas adoptadas en Francia. Recordemos que la Comisión, integrada también por Gregorio Marañón (1887-1960) y Ruiz Falcó, informó del nulo o escaso uso del suero antidiftérico en nuestro vecino país y del empleo de los sueros antiestreptocócicos y antineumocócicos por algunos clínicos franceses ${ }^{43}$. Estas afirmaciones y otras contenidas en el informe emitido por la citada Comisión avivaron el debate y motivaron la intervención del Inspector General de Sanidad, que envío una carta a la Academia de Medicina recabando urgentemente su opinión sobre «los sueros curativos específicos contra los microbios productores de las complicaciones» de la gripe ${ }^{44}$. La respuesta a dicha demanda fue la

40 «Sesión del 26 de octubre de 1918», ARAM, 38, (1918), 403-424, p. 410.

41 «Sesión del 24 de octubre de 1918», Libro de Actas de las Sesiones de las Cortes. Senado, 83, legislatura 1918-1919, pp. 2744-2745; «Sesión del 25 de octubre de 1918», Libro de Actas de las Sesiones de las Cortes. Senado, 83, legislatura 1918-1919, p. 2773. Maestre también denunció la falta de suero antidiftérico y solicitó que el Estado entregara cien caballos al Instituto de Higiene Alfonso XIII para que tratara de mitigarla. MAESTRE, T. (1918b), Carta abierta..., España Médica, 8 (280), 2-5, p. 5; El suero antidiftérico en Madrid, El Heraldo de Madrid, 25-10-1918; Suero antidiftérico, El Liberal, 31-10-1918.

42 «Sesión del 26 de octubre de 1918», ARAM, 38, (1918), pp. 424 y 404. La respuesta de la Academia incluía también la opinión manifestada por Ferrán referente a que la solución para cubrir la demanda podía ser el uso de suero equino normal.

43 Marañón, G., Pittaluga, G., Ruiz Falcó, A. (1918a), Informe sobre el actual estado sanitario de Francia y su identidad con la epidemia gripal en España, El Siglo Médico, 65, 916921; MaraÑón, G., PitTaluga, G., Ruiz Falcó, A. (1918b), Sobre el actual estado sanitario de Francia y su identidad con la epidemia gripal en España, España Médica, 8 (282), 1-3.

44 Archivo de la Real Academia Nacional de Medicina. Carpeta 289 (Papeles diversos. Años 1918-1919). «Carta fechada el 8 de noviembre de 1918 y dirigida a la Real Academia 
sesión de la Academia del 9 de noviembre, en la que Pittaluga se manifestó partidario de no atribuir al suero antidiftérico ninguna acción específica y señaló que en Francia «el empleo de los sueros no específicos» estaba «totalmente descartado» ${ }^{45}$. De hecho, como continuó diciendo Pittaluga, los laboratorios franceses no habían registrado el menor aumento de producción, pero, «en cambio algunos clínicos han empleado los sueros antiestreptocócicos y antineumocócicos» ${ }^{46}$. Pittaluga se expresó en términos similares en la sesión de la Academia del 23 de noviembre, en la que propuso como conclusión de la citada institución el reconocimiento del valor de los sueros antineumocócicos o antiestreptocócicos respectivamente para el tratamiento de las complicaciones neumocócicas y estreptocócicas de la gripe ${ }^{47}$.

\section{EL TRATAMIENTO SUEROTERÁPICO CONTRA LA «GRIPE ESPAÑOLA» Y/O SUS COMPLICACIONES}

Aunque no es posible estudiar y seguir en profundidad el uso que se hizo de los distintos sueros durante la pandemia de gripe, sí pueden apuntarse algunos mínimos datos sobre ello. De lo que no parece haber duda es de que, pese a la mala prensa científica que poseyó el suero antidiftérico entre los profesionales que buscaban actuar conforme al paradigma bacteriológico imperante, dicho suero fue ampliamente utilizado en la medida en que lo permitió su limitada disponibilidad, especialmente durante el segundo brote de la epidemia y, sobre todo, en su momento de máxima intensidad. Se administró preferentemente por vía oral, pero algunos clínicos recurrieron también a las inyecciones hipodérmicas. Las dosis oscilaron desde los 10 centímetros cúbicos cada 8 horas recomendados por Maestre en cuanto se iniciaran los primeros síntomas hasta los 40 centímetros cúbicos empleados por el catedrático de

\footnotetext{
Nacional de Medicina por la Inspección General de Sanidad, Ministerio de la Gobernación». Como se indica en ella, el envío de la carta y su contenido estuvo muy influido por el informe emitido por la Comisión enviada a Francia, por las reacciones frente a dicho informe en distintos foros, como el Real Consejo de Sanidad, y por el acuerdo adoptado en él.

45 «Sesión del 9 de noviembre de 1918», ARAM, 38, (1918), 430-449, pp. 441-442.

46 Ibíd., pp. 442-443. El uso de los sueros antineumocócico y antiestreptocócico en las complicaciones de la gripe fue señalado, entre otros, por Violle. Violle, H. (1918), Pandemia de gripe, España Médica, 8 (280), 5 -7 (traducción del original publicado en La Presse Médicale del 10-10-1918).

47 «Sesión del 23 de noviembre de 1918», ARAM, 38, (1918), 511-528, p. 527.
} 
Medicina de Zaragoza, Ricardo Royo Villanova (1868-1943) ${ }^{48}$. En cuanto a los resultados obtenidos, cabe decir que el entusiasmo de Maestre o Royo — quien aseguraba que había tenido tan sólo 4 defunciones entre más de 6000 enfermos asistidos - no fue compartido por todos los que recurrieron a este recurso terapéutico ${ }^{49}$. De hecho, Martínez Vargas (1861-1948), catedrático de Medicina de Barcelona, reconoció que el «suero antidiftérico, como estimulante de defensas» lo había empleado poco, «por no responder con gran eficacia» ${ }^{50}$. De manera aún más clara se expresó el médico de Cartagena, Manuel Mas Gilabert, quién no otorgó ningún valor a dicho suero y, además, llamó la atención sobre los efectos negativos de su derroche. En su opinión, no sólo «arruina a los enfermos de posición modesta», sino que también provocaba la muerte de niños pequeños por difteria por no disponer de suero ${ }^{51}$.

Los sueros antineumocócico y antiestreptocócico fueron también usados, separadamente o de modo simultáneo para tratar las complicaciones originadas por neumococos y/o estreptococos. Se administraron por vía subcutánea y/o endovenosa. Generalmente se emplearon los sueros de firmas foráneas (del Instituto Pasteur, del Instituto de Berna, de la Casa Burroughs-Wellcome de Londres, etc. $)^{52}$, si bien Pablo Colvée puso a punto un suero antineumocócico que, tras experimentarlo en animales, se utilizó en humanos, escasamente durante la pandemia de 1918-1919 y más ampliamente con motivo de la nueva epidemia de gripe de 1919-192053. Parece que en este último caso se logra-

48 Maestre, T. (1918b), Carta abierta..., España Médica, 8 (280), 2-5, pp. 4-5; Royo Villanova, R. (1918), Opinión de los clínicos, España Médica, 8 (280), 8-11, p. 8.

49 Maestre, T. (1918b), pp. 4-5; Royo Villanova, R. (1918), p. 8.

50 Martínez Vargas (1918), Opinión de los clínicos, España Médica, 8 (280), 1-111918, 8-11, pp. 9-10. El subrayado es nuestro, y con él se trata de llamar la atención que el uso que hizo este autor no fue por considerarlo un recurso específico contra la gripe. El nulo resultado del suero antidiftérico fue también señalado por el médico higienista de Tuy, Darío Álvarez. Álvarez Limeses, D. (1918), Los clínicos nos dicen cómo se trata la gripe..., España Médica, 8 (282), 20-11-1918, p. 6.

51 Esto había ocurrido en un pueblo cercano a Cartagena. MAS GILABERT, M. (1918), Opinión de los clínicos, España Médica, 8 (280), 1-11-1918, 8-11, pp. 10-11.

52 Salvat, A. (1918), Opinión de los clínicos, España Médica, 8 (280), 1-11-1918, 8-11, p. 8; MAS GILABERT, M. (1918), pp. 10-11.

53 ColvÉE, P. (1920), Ensayo de obtención de un suero específico contra la gripe epidémica, Revista de Higiene y Tuberculosis, 13 (143), 80-83. El manuscrito de este trabajo le permitió a Pablo Colvée Reig en 1920 solicitar y conseguir el título de «Académico Corresponsal nacional» de la Real Academia de Medicina. Se aprobó, aunque Murillo no se declaró de acuerdo con el autor cuando decía que únicamente se podía valorar la efectividad de ese suero, al igual que la de todos los demás, en personas infectadas. Archivo de la Real Acade- 
ron mejores resultados que los que, según el higienista Darío Álvarez, brindó el uso de los sueros antineumocócicos durante la pandemia de $1918^{54}$.

Durante la pandemia de 1918 se volvió a recurrir a la autoseroterapia ${ }^{55}$, siendo el médico socialista Salgado uno de sus principales partidarios ${ }^{56}$, y se ensayó el tratamiento con suero de convalecientes, sin resultados definitivos ${ }^{57}$.

Como hemos adelantado, la gripe de 1919-1920 otorgó renovado protagonismo a los sueros como recurso terapéutico. No sólo se recurrió al suero antineumocócico ${ }^{58}$, sino también al suero antidiftérico para combatir las bronconeumonías gripales ${ }^{59}$. Ahora bien, al igual que en la pandemia de 19181919 , los sueros fueron empleados tanto dentro como fuera del paradigma bacteriológico dominante para abordar el tratamiento de las enfermedades infecciosas, y su uso estuvo muy condicionado por razones de índole social, profesional y económica.

7. LA CIENCIA ANTE LA NECESIDAD DE ESTABLECER UNA PROFILAXIS CONTRA LA PANDEMIA DE 1918-1919: LA VACUNA CONTRA LA GRIPE Y/O SUS COMPLICACIONES

$\mathrm{Si}$, como vimos, en el marco del paradigma bacteriológico imperante, un suero específico era el único tratamiento posible contra la epidemia de 19181919, una vacuna específica contra la gripe era el único recurso profiláctico verdaderamente eficaz contra dicha epidemia. Ahora bien, para poder dispo-

mia Nacional de Medicina. Carpeta 292 [Papeles diversos. Año 1920 (II)]. «Expediente nº 24. Pablo Colvé y Reig».

54 Álvarez Limeses, D. (1918), p. 6; Colvée, P. (1920), pp. 80-83.

55 Consistía en inyectar al enfermo cierta cantidad de serosidad obtenida en él mismo, mediante vexicación con vejigatorio cantariado. Uno de los que la utilizó fue Luis Valero. Para mayor información, véase: VALERo CARRERAS, L. (1918), Fundamentos y técnica del tratamiento de las localizaciones respiratorias de la epidemia reinante, España Médica, 8 (284), 10-12-1918, p. 3.

56 De la aplicación gratuita de este procedimiento por Salgado se hizo amplio eco El Socialista en sus páginas, véase por ejemplo: El apostolado del Dr. Salgado. La vacuna gratuita contra la gripe, El Socialista, 17-12-1918 y 27-1-1919, p. 2.

57 Esto fue ensayado por los clínicos franceses sin resultados definitivos. Cfr. MARAÑón, G., Pittaluga, G., Ruiz Falcó, A. (1918b), pp. 1-3.

58 COLVÉE, P. (1920), pp. 80-83.

59 Hernández Briz, B. (1920), La Gripe en el Asilo de San José, Fundación Zorrilla, Inclusa y Colegio de la Paz, El Siglo Médico, 3452, 85-86. 
ner de dicha vacuna resultaba imprescindible resolver el problema de la etiología de la gripe. Sin embargo, como se ha adelantado, esta situación no se produjo y, como señaló el Inspector General de Sanidad, Manuel Martín Salazar, «no [había] vacuna ni medio preventivo específico contra la gripe» ${ }^{60}$. Esta circunstancia unida a la ineficacia de los recursos utilizados habitualmente por la Higiene Pública para luchar contra las epidemias, condujo a los facultativos a que, al final del primer brote, se sintieran «desarmados todavía ${ }^{61}$ en el terreno de la profilaxis pública de las epidemias de gripe, pero a la vez, al igual que con respecto al tratamiento, con la necesidad de tener que responder a las demandas sociales.

Desde su condición de expertos y su deseo de lograr un importante papel en la sociedad española por su alta capacitación científica ${ }^{62}$, los médicos debieron afrontar el segundo brote de la epidemia y tratar de mitigar el «pánico» y la «alarma social». La necesidad de obrar les condujo no sólo a proponer y recomendar un gran número de recursos profilácticos ${ }^{63}$, algunos de eficacia dudosa, sino también a servirse de la ciencia para buscar un medio que fuera capaz de «impedir la propagación del mal» ${ }^{64}$. Como el enemigo a batir era la gripe, una enfermedad que confería inmunidad, como indicó Martín Salazar, «[surgió] inmediatamente en el ánimo del higienista la posibilidad de la profilaxis por medio de las vacunas preventivas $\rangle^{65}$. Con esta idea en mente, al igual que fuera de nuestras fronteras, médicos, farmacéuticos y veterinarios iniciaron investigaciones, que posibilitaron la puesta a punto de algunas vacunas y su ensayo experimental en algunos de nuestros enfermos ${ }^{66}$. En esta

60 «Sesión del 28 de junio de 1918», ARAM, 38, p. 385.

61 Ibíd., p. 385.

62 Los farmacéuticos mantenían una postura similar, hallándose inmersos en un proceso de renovación profesional y de reivindicación de un mayor papel en la sociedad española en el terreno de la salud y la enfermedad. Una muestra de ello es FrANCO, J.P. (1918), Rumbo que se impone, La Farmacia Española, 5-12-1918, 769-773. Para mayor información sobre este tema, véanse: PORRAS GALlO, Ma.I. (2002), pp. 440-472; PORRAS GALlO, Mª.I. (1997a), pp. 109-114.

${ }^{63}$ De hecho, como medios profilácticos se propusieron los cordones sanitarios, el cierre de locales, las desinfecciones externas de individuos, mercancías, locales o vehículos, el uso de mascarillas, el aislamiento, las tradicionales medidas de la Higiene Pública o elementos de carácter social (subsistencias buenas y baratas, viviendas salubres, etc.). PORRAS GALLO, Ma ${ }^{\mathrm{a}}$.I. (2002), pp. 337-346, 352-394; Porras GALlO, Ma.I. (1997a), pp. 108-109; MARTíneZ, M. (1999), pp. 164-165; ECHEVERRI DÁVILA, B. (1993), pp. 138-152.

64 «Sesión del 9 de noviembre de 1918», ARAM, 38, p. 431.

65 Ibíd., p. 431-432.

66 Una visión panorámica y sintética sobre el tema, figura en: PIGA, A., LAMAS, L. (1919), vol. II, pp. 88-99 y 134-166. También resulta de utilidad la consulta de: MARAÑóN, 
labor destacaron el farmacéutico César Chicote (1861-1950) al frente del Laboratorio Municipal de Madrid, los médicos Juan Peset Aleixandre (18861941) ${ }^{67}$, Pablo Colvée ${ }^{68}$ y Adolfo Rincón Arellano ${ }^{69}$, que trabajaron en el Instituto Provincial de Higiene de Valencia bajo la dirección del Delegado sanitario especial del Gobierno Jaime Ferrán (1851-1929), el Catedrático de Higiene de la Facultad de Medicina de Sevilla Antonio Salvat Navarro (18831977) y el doctor Ricardo Moragas de Barcelona $^{70}$.

Al igual que ocurrió con los sueros, coincidiendo con el momento álgido del segundo brote de la pandemia y la difusión del Informe elaborado por la Comisión enviada por el Gobierno a Francia, el debate sobre las vacunas se dinamizó, registrándose interesantes discusiones en la Real Academia de Medicina, en las revistas médico-farmacéuticas, en las sesiones del Real Consejo de Sanidad y de las Cámaras Parlamentarias y en la prensa general ${ }^{71}$. Nuevamente,

G., Pittaluga, G., Ruiz Falcó, A. (1918a), pp. 916-921; FreiXas i FreiXas, J. (1919), La medicació específica en el tractament de la grip. En Tercer Congrès de metges de llengua catalana, Barcelona, Imprempta Badia, 613-627, pp. 620-623.

67 Director del Laboratorio Provincial del Instituto Provincial de Higiene de Valencia desde 1916 tras haber desplegado una brillante actividad en el Laboratorio Municipal de Sevilla. BARONA, C. (2006), Las políticas de la salud. La sanidad valenciana entre 1855 y 1936, Valencia, Universidad de Valencia, p. 114.

68 Director del Laboratorio Bacteriológico Municipal de Valencia. BARONA, C. (2006), pp. 114-136.

69 Director del Laboratorio de Sanidad Militar. BAronA, C. (2006), p. 136.

70 Para obtener más información sobre las distintas vacunas preparadas por los profesionales sanitarios mencionados, además de remitir a la bibliografía citada en la nota 66 , resulta de utilidad la consulta de: «Sesión del 9 de noviembre de 1918», ARAM, 38, pp. 435-436.; FERrÁn, J., Rincón, A., COlvÉE, P., PESET, J. (1918), Estudios experimentales sobre la gripe actual, practicadas en el Instituto Provincial de Higiene de Valencia [La epidemia reinante], Revista de Higiene y Tuberculosis, 11 (126), 256-260; SAlvat NaVArro, A. (1926), Tratado de Higiene, Barcelona, Manuel Marín, t. II ( ${ }^{\text {a }}$ ed.), pp. 286-288; MoragAS y Gracia, R. (1919), Nota sobre la vacunación preventiva de la bronconeumonía gripal, Policlínica, 7 (74), 165-167; ChabÁs, J. (1918), Más de la epidemia reinante, Revista de Higiene y Tuberculosis, 11 (127), 265-274; SACABEJos, H., TALENS, E. (1919a), Gripe, [Reseña de infecciones], Revista de Higiene y Tuberculosis, 12 (130), 67-68; SACABEJOS, H., TALENS, E. (1919b), Gripe, [Reseña de infecciones], Revista de Higiene y Tuberculosis, 12 (137), 240-241.

71 Marañón, G., Pittaluga, G., Ruiz Falcó, A. (1918a) y (1918b); Mayoral, P, (1918), La Gripe, El Siglo Médico, 3380, p. 800; VVAA (1918), Opinión de los clínicos, España Médica, 280, 8-11; Comisión médica a París. Estudio de la Gripe, El Heraldo de Madrid, 5-11-1918, p. 2. En El Heraldo de Madrid, del 25 de octubre de 1918, p. 3, se recogía la nota del Director del Laboratorio Municipal sobre la vacuna que se había preparado en 
desde la necesidad de obrar, bajo la presión de las críticas que la sociedad estaba formulando y con el respaldo del Informe elaborado por Pittaluga, Marañón y Ruiz Falcó y el acuerdo del Real Consejo de Sanidad ${ }^{72}$, el Inspector General de Sanidad reclamó con urgencia la opinión de la Real Academia de Medicina sobre «el uso de vacunas preventivas de la gripe y sus complicaciones como medio de establecer una profilaxis pública racional contra ese padecimiento» ${ }^{73}$. La respuesta llegó en la sesión de la Academia del 9 de noviembre. En ella, las circunstancias que concurrían marcaron claramente el tono del debate. Se resaltó la «inocuidad» de las vacunas preparadas hasta ese momento, su capacidad para «impedir la infección» gripal y el valor que ello tenía ante la gravedad que alcanzaba la epidemia ${ }^{74}$. Desde la Inspección General de Sanidad se apeló a los buenos resultados ofrecidos por los estudios y experiencias llevados a cabo en instituciones científicas de prestigio, como el Instituto Rockefeller de los Estados Unidos o el Instituto Pasteur de París, y se quiso transmitir «la esperanza de encontrar un medio preventivo contra la difusión de la gripe y sus complicaciones» como resultado de las investigaciones y estudios experimentales en curso, tanto dentro como fuera de nuestro país ${ }^{75}$. Por todo ello y, sobre todo, porque las vacunas eran para el Inspector General de Sanidad «la única base científica para instituir una profilaxis pública contra la gripe», solicitó el voto favorable de la Academia y la recomendación de que se alentara a los laboratorios nacionales a seguir trabajando en la búsqueda y puesta a punto de una vacuna preventiva contra la gripe ${ }^{76}$.

Sin embargo, dado que la nueva ciencia no era capaz de resolver el problema de la etiología de la gripe, esta petición debía ser matizada. De ahí que Martín Salazar optara por subrayar que «no [había] duda de que las complica-

dicho laboratorio y la opinión favorable de Francos Rodríguez, que «aplaudía la orientación del laboratorio, puesto que la terapéutica moderna está basada en vacunas y sueros».

72 El Real Consejo de Sanidad era favorable a que se favoreciera la realización de estudios sobre las vacunas contra la gripe en los laboratorios españoles para poder disponer de este recurso preventivo. Cfr. Archivo de la Real Academia Nacional de Medicina. Carpeta 289 Papeles diversos. Años 1918-1919. «Carta de la Inspección General de Sanidad. Ministerio de la Gobernación del 8 de noviembre de 1918».

73 Archivo de la Real Academia Nacional de Medicina. Carpeta 289 Papeles diversos. Años 1918-1919. «Carta de la Inspección General de Sanidad. Ministerio de la Gobernación del 8 de noviembre de $1918 »$.

74 «Sesión del 9 de noviembre de 1918», ARAM, 38, p. 433.

75 Ibíd., p. 432.

76 Ibíd., pp. 433-435. 
ciones mortales [estaban] determinadas por neumococos y estreptococos» ${ }^{77} \mathrm{y}$, en consonancia con ello, hiciera hincapié en el valor de las vacunas para evitar las complicaciones de la gripe. Esta opinión fue compartida, entre otros, por el médico Francisco Murillo, el farmacéutico Chicote y el veterinario García Izcara (1859-1927), y en términos similares fue formulada la respuesta de la Academia de Medicina al Ministro de la Gobernación ${ }^{78}$. Desde la citada institución se indicó «la conveniencia de estimular con todos los medios la preparación y el empleo de las vacunas procedentes de los gérmenes que en la inmensa mayoría de los casos provocan las complicaciones broncopulmonares graves de la infección gripal» ${ }^{79}$. Se trataba, por tanto, de utilizar vacunas mixtas que contuvieran neumococos y estreptococos, aunque la Academia sugirió «una vacuna neumocócica pura», como la que fue puesta a punto en el Instituto Provincial de Higiene de Valencia ${ }^{80}$.

Ante los resultados y las limitaciones del laboratorio, por tanto, cabía únicamente resaltar el valor de las vacunas contra las complicaciones de la «gripe española». De hecho, dada la situación, algunos médicos se mostraron incluso partidarios de limitar su aplicación a los enfermos y reclamaron su uso desde el inicio mismo del proceso para evitar las complicaciones gripales ${ }^{81}$.

\section{PRINCIPALES CARACTERÍSTICAS DE LAS VACUNAS ESPAÑOLAS EMPLEADAS CONTRA LA PANDEMIA DE 1918-1919}

Como se ha adelantado, médicos, farmacéuticos y veterinarios pusieron a punto y aplicaron las primeras vacunas empleadas contra la gripe de 19181919 en nuestro país en el marco que acabamos de describir. La mayoría de las vacunas preparadas y utilizadas fueron vacunas mixtas ${ }^{82}$. De hecho, salvo la vacuna neumocócica del Instituto Provincial de Higiene de Valencia, el resto contuvieron neumococos y estreptococos combinados con otros gérmenes, que variaron en cada caso. Así, la vacuna del Laboratorio Municipal de

77 Ibíd., p. 434.

78 «Sesión del 9 de noviembre de 1918», ARAM, 38, pp. 443, 446 y 448. «Sesión del 12 de noviembre de 1918», ARAM, pp. 460-461.

79 «Sesión del 9 de noviembre de 1918», ARAM, 38, p. 448.

80 Ibíd., pp. 448-449.

81 Ibíd., pp. 443-446. «Sesión del 1 de febrero de 1919», ARAM, 39, pp. 22-23.

82 Acerca de las vacunas utilizadas contra la pandemia de gripe de 1918-1919, tanto dentro como fuera de nuestras fronteras, puede consultarse: PIGA, A., LAMAS, L. (1919), t. I, p. 281 y ss.; t. II, pp. 88-99 y 134-166. 
Madrid contenía también micrococcus catharralis, la de Ricardo Moragas llevaba además estafilococos y bacilos pseudodiftéricos, y la de Antonio Salvat meningococos y bacilos de Pfeiffer ${ }^{83}$.

Una composición similar tuvieron las vacunas empleadas fuera de nuestras fronteras ${ }^{84}$. De hecho, en Francia, nuestro referente principal tras la visita de la Comisión gubernamental enviada a dicho país para estudiar la epidemia de gripe, se emplearon tres tipos distintos de vacunas: vacunas neumocócicas, vacunas mixtas de estreptococos y neumococos, o vacunas mixtas de estreptococos, neumococos y bacilos de Pfeiffer ${ }^{85}$. Una vacuna mixta con la misma composición que esta última fue la adoptada por la Conferencia de médicos ingleses, que, bajo la presidencia del Coronel-médico William Leishman, se celebró en noviembre de 1918 en Londres en el War Office ${ }^{86}$. Dicha vacuna se aplicó al Ejército por el Royal Army Medical College y a la Marina por el Royal Naval College, pero también a la población civil por el Departamento médico del Local Government Board ${ }^{87}$.

$\mathrm{Si}$ el tipo de vacunas usadas fue similar no ocurrió lo mismo con las dosis empleadas. De hecho, las vacunas francesas fueron inyectadas «en dosis extraordinariamente elevadas», mientras que las dosis de las vacunas españolas fueron mucho menores ${ }^{88}$. Se aplicaron normalmente dos inyecciones: la primera de ellas de medio centímetro cúbico y la segunda de un centímetro cúbico. El intervalo de separación entre ambas dosis varió desde los cuatro días en el caso de la vacuna del Laboratorio municipal de Madrid hasta ocho con la vacuna de Ricardo Moragas ${ }^{89}$.

83 «Sesión del 9 de noviembre de 1918», ARAM, 38, p. 435-436. FERrÁn, J., RinCÓn, A., Colvée, P., Peset, J. (1918), pp. 256-257; SAlvat NAvarro, A. (1926), pp. 286-288; MoRAGAS Y GRACIA, R. (1919), pp. 165-167; ChABÁs, J. (1918), pp. 265-274; SACABEJOS, H., TAlens, E. (1919a), pp. 67-68; SACABEJOS, H., TAlens, E. (1919b), pp. 240-241.

84 Información sobre las vacunas aplicadas fuera de nuestro país, puede encontrarse en: Marañón, G., Pittaluga, G., Ruiz Falcó, A. (1918a) y (1918b); Sacabejos, H. (1920); PigA, A., LAMAS, L. (1919), t. II, pp. 94-95.

85 «Sesión del 9 de noviembre de 1918», ARAM, 38, pp. 440-441; MARAÑón, G., PITTALUGA, G., Ruiz FAlCó, A. (1918b), pp. 2-3.

86 «Sesión del 19 de noviembre de 1918», ARAM, 38, pp. 487-488.

87 Ibíd., p. 488.

88 «Sesión del 9 de noviembre de 1918», ARAM, 38, pp. 440-441.

89 «Sesión del 9 de noviembre de 1918», ARAM, 38, p. 435-436. FERRÁn, J., RINCÓN, A., Colvée, P., Peset, J. (1918), pp. 256-257; Salvat Navarro, A. (1926), pp. 286-288; MoRAGAS y GRACIA, R. (1919), pp. 165-167; ChABÁs, J. (1918), pp. 265-274; SACABEJOS, H., TAlens, E. (1919a), pp. 67-68; SACABEJOS, H., TAlens, E. (1919b), pp. 240-241. 
A tenor de la información proporcionada por los investigadores, una vez preparadas las vacunas con los gérmenes elegidos conforme al resultado de las investigaciones realizadas en la sangre y los esputos de enfermos de gripe y/o en los tejidos procedentes de las autopsias efectuadas a cadáveres de fallecidos por la epidemia ${ }^{90}$, se procedió a hacer ensayos y pruebas en los distintos laboratorios para demostrar su inocuidad ${ }^{91}$. Establecida la inocuidad, fueron los propios profesionales que las habían puesto a punto los primeros en vacunarse con el fin de desvanecer los recelos y temores frente a ellas ${ }^{92}$.

Seguidamente, se inició su aplicación práctica a personas sanas y, en algunos casos, también a enfermas sin producirse al parecer más que ligeras reacciones locales y alguna reacción febril ${ }^{93}$. Aunque se pretendió en muchos casos hacer vacunaciones masivas en nuestro país, no hay noticias de que, como en Francia, se llevaran a cabo «experimentaciones en grandes agrupaciones humanas», en pueblos enteros que el Gobierno francés puso a disposición de los investigadores para que se aplicaran los distintos tipos de vacunas ${ }^{94}$. Con la información con que contamos resulta difícil establecer con certeza el número de vacunaciones practicadas con cada una de las vacunas españolas. De hecho, según Martín Salazar, con la vacuna del Instituto Provincial de Higiene de Valencia se vacunó a una «infinidad de personas» ${ }^{95}$. Sin embargo, Carmen Barona ha indicado recientemente que su uso se vio limita-

90 Mientras que la vacuna del Laboratorio municipal de Madrid, la de Salvat y la de Moragas fueron preparadas con los gérmenes aislados en la sangre y en los esputos de los enfermos de gripe, la vacuna del Instituto Provincial de Higiene de Valencia incluyó además y, sobre todo, los gérmenes aislados en los tejidos procedentes de las autopsias efectuadas a 29 cadáveres de fallecidos por la epidemia. «Sesión del 9 de noviembre de 1918», ARAM, 38, p. 435-436. Ferrán, J., Rincón, A., Colvée, P., Peset, J. (1918), pp. 256-257; SAlvat NavaRRO, A. (1926), pp. 286-288; MORAGAS Y GraCiA, R. (1919), pp. 165-167; ChABÁs, J. (1918), pp. 265-274; SACABeJos, H., TAlens, E. (1919a), pp. 67-68; SaCABEJos, H., TAlens, E. (1919b), pp. 240-241.

91 Con los datos con que contamos, proporcionados por los distintos investigadores, no es posible hacer una valoración sobre la corrección en el procedimiento empleado.

92 «Sesión del 9 de noviembre de 1918», ARAM, 38, p. 435-436. FERRÁn, J., RINCÓN, A., Colvée, P., Peset, J. (1918), pp. 256-257; Salvat Navarro, A. (1926), pp. 286-288; MoRAGAS Y GRACIA, R. (1919), pp. 165-167.

93 «Sesión del 9 de noviembre de 1918», ARAM, 38, p. 435-436. FERRÁn, J., Rincón, A., Colvée, P., Peset, J. (1918), pp. 256-257; Salvat Navarro, A. (1926), pp. 286-288; MoRAGAS Y GRACIA, R. (1919), p. 167.

94 «Sesión del 9 de noviembre de 1918», ARAM, 38, p. 440.

95 Ibíd., p. 437. 
do por la finalización de la epidemia ${ }^{96}$. Por su parte, Salvat indicó años más tarde de la pandemia que los resultados alcanzados con su vacuna habían superado sus esperanzas, ya que «más de cinco mil vacunaciones consiguieron éxitos notables» ${ }^{97}$. Además de los alumnos de Medicina, que actuaron como auxiliares sanitarios en los pueblos epidemiados, recibieron la vacuna de Salvat los habitantes de Valverde del Camino y de Aracena ${ }^{98}$. En los dos casos comentados, las vacunas se aplicaron únicamente a personas sanas. A su vez, la vacuna de Moragas fue administrada a 36 mujeres y 50 hombres internados en el Manicomio del Hospital de la Santa Creu de Barcelona con buenos resultados en la prevención de la bronconeumonía gripal, pero también a 20 enfermos particulares de Moragas (12 hombres y 8 mujeres $)^{99}$.

Por otro lado, la vacuna del Laboratorio Municipal de Madrid, uno de los laboratorios que tuvo mayor protagonismo y relevancia durante la pandemia de 1918-1919100, se aplicó al personal del laboratorio (camilleros, encargados de manejar la ropa de los enfermos en las estufas de desinfección, etc.) que mayor peligro de contagio tenía, pero también al jefe y a los profesores de la Sección de vacunas, a sus familiares y a otros individuos del laboratorio ${ }^{101}$. Igualmente se administró a los enfermos de las salas de Marañón del Hospital Provincial de Madrid desde el $2^{\circ}$ o 3er día de enfermedad y el Director del Laboratorio Municipal de Madrid ofreció dicha vacuna a todos los médicos que la solicitaran para que efectuaran «todos los ensayos posibles sobre su eficacia» y dieran «con toda tranquilidad su opinión» ${ }^{102}$. De la disponibilidad de la vacuna y de su aplicación con carácter experimental se hizo eco alguno de los diarios ${ }^{103}$.

96 BARONA Vilar, C. (2006), p. 136.

97 Salvat Navarro, A. (1926), p. 287.

98 En su texto de 1926, Salvat dice que toda la información referente a la puesta a punto y aplicación de su vacuna, que no la incluye en el libro por no ser apropiado a las condiciones del mismo, figuraron en los artículos que publicó en la revista Plus Ultra de Madrid. Cfr. Salvat Navarro, A. (1926), pp. 287-288. Hasta el momento no he podido tener acceso a dichos artículos.

99 Moragas y Gracia, R. (1919), pp. 166-167; CHABÁs, J. (1918), pp. 265-274; SACABejos, H., Talens, E. (1919a), pp. 67-68; SACABejos, H., TAlens, E. (1919b), pp. 240-241.

100 Porras Gallo, Ma .I. (1997b), El Laboratorio Municipal de Madrid y la epidemia de gripe de 1918-19, Anales del Instituto de Estudios Madrileños, 37, 585-591.

101 «Sesión del 9 de noviembre de 1918», ARAM, 38, pp. 435-436.

102 Ibíd., p. 437.

103 Informe del Señor Chicote, $A B C, 28-10-1918$, p. 15. Este mismo diario volvería a ocuparse de la vacuna del Laboratorio Municipal de Madrid durante el tercer brote de la pande- 
Como vemos, el farmacéutico Chicote, que comenzó las investigaciones conducentes a la obtención de una «vacuna» de posible utilidad para «prevenir las complicaciones pulmonares de la gripe» ${ }^{104}$ por indicación del Inspector General de Sanidad en una de las sesiones del Real Consejo de Sanidad, contó con la colaboración de uno de los médicos más relevantes del momento para aplicar experimentalmente su vacuna. Esta colaboración con Marañón y otros profesionales influyentes de los principales hospitales madrileños se mantuvo también para la puesta a punto de la vacuna. De hecho, el Director del Laboratorio Municipal se sirvió para ello de los enfermos procedentes de la Beneficencia Municipal, del Hospital Militar de Carabanchel y, sobre todo, del Hospital Provincial de Madrid de las salas de los doctores Francisco Huertas, José Codina (1867-1934) y Marañón.

Aunque es cierto que tradicionalmente se han empleado las instituciones de custodia para la puesta a punto y el ensayo de las vacunas ${ }^{105}$, resulta llamativa esa búsqueda de apoyo en el sector médico influyente y en las autoridades sanitarias en un momento en el que se advertían las grandes posibilidades que se podían abrir para quién dispusiera de una —o de la mejor - vacuna que consiguiera reducir los estragos de la gripe. Para valorar adecuadamente el significado de dicho proceder recordemos que Chicote era farmacéutico y que médicos, farmacéuticos y veterinarios se estaban disputando la primacía en la fabricación y aplicación de los sueros y vacunas desde finales del siglo $\mathrm{XIX}^{106}$ y esta situación se acentuó durante la pandemia ${ }^{107}$. Chicote era consciente de esa situación. De ahí su insistencia ante la Real Academia de Medicina de que no le animaba «ningún (...) interés profesional», sino que su único interés era «el de la Sanidad; el de conseguir algún efecto útil en la

mia; La Salud en España, $A B C$, 19-2-1919, p. 16; Sensacional descubrimiento. Vacuna contra la gripe, $A B C, 27-3-1919$.

104 Ibíd., p. 435.

105 HALPERN, S. (2004), p. 76.

106 Porras Gallo, Mª.I. (1998), Antecedentes y creación del Instituto de Sueroterapia, Vacunación y Bacteriología de Alfonso XIII, Dynamis, 18, 81-105, p. 89.

107 Tal y como denunciaron los farmacéuticos en sus principales órganos de expresión, los médicos alcanzaron mayor protagonismo en este terreno durante la pandemia. Críticas a algunos puntos de la Reglamentación de la elaboración y venta de sueros y vacunas, La Farmacia Española, 20-10-1919, p. 473; FRANCO, J.P. (1919), ¿Rectificación? No satisface, La Farmacia Española, 1-11-1919, 484-486; Elaboración y venta de vacunas y sueros, La Farmacia Española, 1-12-1919, 536-537; Renovación y regeneración sanitarias (última de la serie), La Farmacia Moderna, 25-7-1919, 161-162. Más información sobre el mismo tema figura en La Farmacia Moderna, 25-9-1919, p. 219 y La Farmacia Moderna, 25-11-1919, 277-279. 
profilaxis o en la terapéutica de la epidemia» ${ }^{108}$. A tenor de lo que venimos exponiendo, parece apropiado plantear que el director del Laboratorio Municipal de Madrid trataba de abrirse un hueco en el atractivo mercado sobre vacunas y sueros en creciente expansión estableciendo una relación de colaboración con el sector médico.

A pesar de la positiva valoración realizada normalmente por los propios autores de las diferentes vacunas, con los datos disponibles resulta difícil evaluar su efectividad real desde el punto de vista profiláctico para luchar contra la gripe. De hecho, la información ofrecida a lo largo de las páginas precedentes pone de relieve que la inmunización artificial contra la gripe se encontraba aún en una fase experimental ${ }^{109}$. En efecto, Francisco Murillo indicó que aún no se había publicado un estudio formal con los resultados obtenidos con la aplicación de la vacuna inglesa de Leishman, y que su utilización en los ejércitos francés e inglés parecía haber ofrecido escasos resultados ${ }^{110}$. A la vista de ello, en su opinión, las vacunas no podían tener «plena aplicación social». De ahí que las autoridades sanitarias de algunos países, como los Estados Unidos, tuvieran que alertar a la población contra los pretendidos éxitos de estos recursos profilácticos, señalados en los anuncios de los fabricantes de algunas vacunas ${ }^{111}$.

\section{A MODO DE EPÍLOGO}

Como se ha puesto de relieve, las expectativas depositadas por los profesionales sanitarios en la Ciencia de los sueros y las vacunas al inicio de la pandemia de gripe de 1918-1919 no se vieron cumplidas. Es cierto que el laboratorio carecía de microscopio electrónico en esos momentos, pero sobre todo lo que realmente faltó fue el necesario consenso científico para abordar correctamente el tratamiento y la profilaxis de la «gripe española» dentro del paradigma bacteriológico.

Ahora bien, la necesidad de atender a una situación crítica — marcada por la gravedad y magnitud de la epidemia, el fallo de los recursos terapéuticos y profilácticos empleados normalmente contra las enfermedades epidémicas,

108 «Sesión del 9 de noviembre de 1918», ARAM, 38, p. 436.

109 Ibíd., p. 447. «Sesión del 23 de noviembre de 1918», ARAM, 38, p. 512.

110 «Sesión del 1 de febrero de 1919», ARAM, 39, p. 23.

111 «Sesión del 9 de noviembre de 1918», ARAM, 38, p. 447. «Sesión del 1 de febrero de 1919», ARAM, 39, p. 23. 
las demandas y críticas de la sociedad en una compleja coyuntura política, económica y social - condujo a médicos y farmacéuticos (que estaban inmersos en un proceso de reorganización profesional) a relativizar la incapacidad de la ciencia y a cifrar en sueros y vacunas la lucha terapéutica y profiláctica contra la gripe de 1918-1919.

Las elevadas cifras de mortalidad parecen ir en contra de las positivas valoraciones efectuadas por los propios profesionales que pusieron a punto y/o usaron sueros y vacunas para combatir la pandemia. Sin embargo, no cabe duda de los posibles beneficios logrados en diferentes ámbitos. De modo más inmediato hay que señalar su capacidad para procurar cierta tranquilidad a la población, pero tampoco se debe olvidar su valor para mejorar la credibilidad social de médicos, farmacéuticos y veterinarios, así como para procurar pingües beneficios económicos a dichos profesionales al acceder al prometedor mercado de la fabricación de sueros y vacunas. En este sentido, parece también oportuno mencionar las mejoras legislativas introducidas en este campo, como el Real Decreto de 10-X-1919 y la Real Orden de 27-X-1919 sobre sueros y vacunas ${ }^{112}$. Igualmente, se hace necesario valorar el positivo papel que la actividad científica desplegada durante la gripe de 1918-1919 para buscar y poner a punto un suero y una vacuna eficaces contra dicha enfermedad pudo desempeñar en la deseada modernización sanitaria de nuestro país. De hecho, no parece haber duda del desarrollo alcanzado por el Laboratorio Provincial del Instituto Provincial de Higiene de Valencia o por el Laboratorio Municipal de Madrid durante la pandemia ${ }^{113}$, ni tampoco de las mejoras introducidas en algunos laboratorios privados, $\mathrm{y}$, sobre todo, tal y como denunciaron las principales revistas farmacéuticas, del importante número de nuevos laboratorios especializados privados creados durante la pandemia o inmediatamente después bajo la dirección de médicos, integrantes algunos de ellos de la plantilla del Instituto Nacional de Higiene Alfonso XIII ${ }^{114}$. Quizás

112 Rodríguez Nozal, R., González Bueno, A. (2005), Entre el arte y la técnica. Los orígenes de la fabricación industrial del medicamento, Madrid, Consejo Superior de Investigaciones Científicas, pp. 365-383. El RD de 10-X-1919 no fue bien recibido por los farmacéuticos por entender que la dirección de los laboratorios encargados de la producción de sueros y vacunas les debía corresponder a farmacéuticos y veterinarios, pero no a los médicos.

113 Barona, C. (2006), pp. 114 y 136; Porras Gallo, Ma..I. (1997b), pp. 585-591.

114 Información sobre el mismo tema figura en: Elaboración y venta de vacunas y sueros, La Farmacia Española, 1-12-1919, 536-537; Renovación y regeneración sanitarias (última de la serie), La Farmacia Moderna, 25-7-1919, 161-162, así como en: La Farmacia Moderna, 25-9-1919, p. 219 y La Farmacia Moderna, 25-11-1919, 277-279. 
esta circunstancia permita explicar el nulo protagonismo que dicho Instituto tuvo en el tema que hemos examinado.

Por su parte, la prensa general y obrera revisada desempeñó un rol muy discreto. Se hizo eco puntual del debate sobre el valor del controvertido suero antidiftérico o de la iniciativa del médico socialista Salgado, así como de la disponibilidad y uso experimental de la vacuna del Laboratorio Municipal de Madrid.

Fecha de recepción: 20 de octubre de 2007.

Fecha de aceptación: 13 de febrero de 2008. 
